\title{
Fexofenadine hydrochloride in the treatment of allergic disease: a review
}

\author{
David Axelrod' \\ Leonard Bielory ${ }^{2}$ \\ Division of Allergy, Immunology \\ and Rheumatology, UMDNJ-New \\ Jersey Medical School, \\ 'Department of Medicine, \\ ${ }^{2}$ Departments of Medicine, \\ Pediatrics, Ophthalmology \\ and Visual Sciences, \\ Newark, New Jersey, USA
}

Correspondence: Leonard Bielory UMDNJ - New Jersey Medical School, 90 Bergen Street, DOC Suite 4700, Newark, New Jersey 07103, USA

Tel + I 9739722768

Fax + I 9739722769

Email bielory@umdnj.edu

\begin{abstract}
Fexofenadine is a selective, non-sedating H1 receptor antagonist, marketed in the United States since 2000. The FDA approved an oral suspension in 2006, for the treatment of seasonal allergic rhinitis and chronic idiopathic urticaria in children. The tablet, capsule, and oral suspension are bioequivalent. Although fexofenadine does not use P450 CYP 3A4 it does interact with a number of drugs at P-glycoprotein and organic anion transporter polypeptides. The risk of toxicity from other drugs may increase with the administration of fexofenadine. Orange and grapefruit juices reduce the bioavailability of fexofenadine. Fexofenadine has been shown to have an impact on inflammatory mediators, other than histamine, such as decreasing the production of $\mathrm{LTC}_{4}, \mathrm{LTD}_{4}, \mathrm{LTE}_{4}, \mathrm{PGE}_{2}$, and $\mathrm{PGF}_{2 \alpha}$; inhibiting cyclo-oxygenase 2, thromboxane; limiting iNOS generation of NO; decreasing cytokine levels (ICAM-1, ELAM-1, VCAM-1, RANTES, I-TAC, MDC, TARC, MMP-2, MMP-9, tryptase); and diminishing eosinophil adherence, chemotaxis, and opsonization of particles. These effects may provide benefit to some of the inflammatory responses of an acute allergic reaction and provide a basis for future development of $\mathrm{H} 1$ antagonists with stronger anti-inflammatory effects. These studies also support the contention that fexofenadine is effective for the treatment of allergic rhinits and chronic idiopathic urticaria.
\end{abstract}

Keywords: fexofenadine, allergy, oral suspension, formulations, pharmacology

\section{Introduction}

The allergic response in people with atopic disorders involves exposure of the immune system to the antigen (Leung 1998), antigen presentation (Fokkens et al 1991), mediator release with amplification signals (Grewal and Flavell 1996; Vercelli et al 1989), and production of antigen specific IgE, which binds to mast cells. (Ishizaka and Ishizaka 1977). Upon re-exposure to the allergen, bridging of the mast cell bound allergen specific IgE results in the release of preformed and newly synthesized bioactive and pro-inflammatory mediators (Hirano 1989), which results in the symptoms of allergic rhinitis and chronic idiopathic urticaria, and contributes to the symptoms of atopic dermatitis and allergic asthma.

Antihistamines form the cornerstone of treatment for allergic disorders. Fexofenadine has been marketed in the US as a selective $\mathrm{H}_{1}$ antagonist since 2000 . However, the drug appears to exhibit some anti-inflammatory activity. The US Food and Drug Administration (FDA) approved an oral suspension of fexofenadine on October 16, 2006. The approval is for twice-daily dosing, for the treatment of symptoms associated with seasonal allergic rhinitis, in patients 2 to 11 years of age, and for the treatment of symptoms of chronic idiopathic urticaria, in patients 6 months to 11 years of age.

The studies cited in this text provide information based upon other oral formulations of fexofenadine. Information on fexofenadine oral suspension remains sparse. Information based upon efficacy studies financially supported only by the manufacturer is not included, unless stated in the text. 


\section{Bioequivalence of oral suspension and solid formulations of fexofenadine}

Morrison and Sahasranaman (2007) administered fexofenadine $30 \mathrm{mg}$ by tablet or by oral suspension to 53 normal adult subjects. Their subjects reached maximum blood fexofenadine concentrations at 1 hour for the oral suspension and 1.5 hour for the tablet. They found equivalent areas under the curves for the oral suspension and the tablet formulation, suggesting bioequivalence of fexofenadine oral suspension and fexofenadine capsules. In a study focusing on the oral formulations, Grubbe et al (2007) evaluated the pharmacokinetics of fexofenadine oral suspension in 50 children, aged 2 to 5 years, which demonstrated the mean maximum plasma concentration of $224 \mathrm{ng} / \mathrm{mL}$, and the mean area under the plasma concentration curve of $898 \mathrm{ng}-\mathrm{h} / \mathrm{mL}$. In capsule formulations in a double-blind, two-way crossover study in children with allergic rhinitis (with a mean age of 9.8 years, a mean height of $134 \mathrm{~cm}$ and a mean weight of $32.1 \mathrm{~kg}$ ), Simons et al (1996) administered 30 or $60 \mathrm{mg}$ of fexofenadine as a capsule and demonstrated the mean maximum plasma concentrations after the $30 \mathrm{mg}$ dose of $78 \mathrm{ng} / \mathrm{mL}$, and the mean maximum concentrations after the $60 \mathrm{mg}$ dose of $286 \mathrm{ng} / \mathrm{mL}$. They found no dose-dependent kinetics in the doses studied and no difference in the clearance rates or the mean terminal elimination half-life values after both doses. In another capsule and tablet formulation study designed as open-label, randomized crossover studies in healthy male non-smokers 18 to 43 years of age, within $10 \%$ of ideal body weight, Stoltz et al (1997) found that the relative bioavailability of fexofenadine capsules is $89 \%$ to $93 \%$ compared to the tablet formulation. Food decreased the area under the curves by $17 \%$ for the capsule and by $25 \%$ for the tablet compared to administration of the fexofenadine under a fasting state. Food did not change the proportionality of the fexofenadine pharmacokinetics.

These studies suggest that fexofenadine is bioequivalent in its three oral formulations.

\section{Pharmacokinetics}

In an industry-based ${ }^{1}$ study, Robbins et al (1998) studied the pharmacokinetics of fexofenadine in 24 healthy male adult volunteers. The drug was undetectable at 48 hours

${ }^{1}$ Hoechst Marion Roussel first marketed fexofenadine. In 1999, Hoechst AG (parent company to Hoechst Marion Roussel) merged with Rhône-Poulenc to form Aventis, which was absorbed into Sanofi-Aventis in 2004. after a single dose, and percent drug recovered in the urine ranged from $7.6 \%$ to $11.8 \%$. In another industry-based study, Russell et al (1998) found similar pharmacokinetics, in healthy male adults, for both the single dose and twicedaily dose of fexofenadine, administered as an oral solution, with $80 \%$ of the administered drug passing through the intestinal tract (Russell et al 1998). These two studies suggest that the majority of the drug is excreted through the intestinal tract, with a small component via the kidneys, mostly unchanged.

Although high doses of fexofenadine do not appear to provide much toxicity, interaction with other drugs that use the P450 CYP3A4 degradation pathway, P-glycoprotein and the organic anion transporter peptides, prominent transporter proteins, may increase the risks of adverse events (Shukla et al 2008). Concomitant exposure to prescription and nonprescription drugs, as well as food, may significantly alter the blood and tissue levels of medications, as well as alter the risks to those medications. Factors that may affect the drug-drug and drug-food interactions include biodegradative pathways and transport mechanisms, particularly via the multi-drug transporters P-glycoprotein and organic anion transporter (Table 1) (Adenot et al 2004; Akiyama et al 1988; Baltes et al 2007; Charuk et al 1994; Chiou et al 2000; Choi et al 1998; Crowe et al 2006a, b; DiDiodato and Sharom 1997; Doran et al 2005; Ejsing et al 2007; Elsinga et al 2004; Faassen et al 2003; Feng et al 2008; Fromm 2000; Garrigues et al 2002; Gouaze et al 2005; Hanko et al 2003; Hayeshi et al 2006; Ibrahim et al 2000; Ito et al 1997; Jette et al 1995; Johnson 2002; Ketabi-Kiyanvash et al 2003; Kim and Kim 2002; King et al 2001; Lee and Lee 2002; Leung and Bendayan 1999; Ling 1992; Litman et al 2003; Loo et al 2003; Makowski and Pikula 1997; Mollgard et al 2001; Neuhoff et al 2000; Orlowski and Garrigos 1999; Pascaud et al 1998; Rebbeor and Senior 1998; Safa and Safa 2004; Savolainen et al 2002; Schinkel et al 1996; Sharom 1997; Shirasaka et al 2006; Shukla et al 2008; Smit et al 1998; Storch et al 2007; Terao et al 1996; Wang et al 2006; Weiss et al 2003).

Although sterioisomers are commonly found to have some preferential biological and pharmacological effects (Bielory et al), Miura et al (2007) did not find any difference in the pharmacokinetics of fexofenadine enantiomers in healthy subjects. They found that neither enantiomer underwent metabolism by CYP3A4. In addition, alfentanil, a selective inhibitor of the P450 CYP3A4 degradative pathway, did not significantly compete with fexofenadine (Kharasch et al 2005). Therefore, it appears that fexofenadine does not significantly interact with the P450 CYP3A degradative pathway. However, in a study 
Table I Site and effect of drug interactions with fexofenadine

\begin{tabular}{|c|c|c|}
\hline Drug & Interaction & $\begin{array}{l}\text { Effect of interaction on fexofenadine } \\
\text { peak concentration }\end{array}$ \\
\hline Ketoconazole & Inhibit P-glycoprotein & $\begin{array}{l}\text { Decrease intestinal absorption and increased } \\
\text { fexofenadine peak concentration }\end{array}$ \\
\hline Itraconazole & Inhibit P-glycoprotein & $\begin{array}{l}\text { Decrease intestinal absorption and increased } \\
\text { fexofenadine peak concentration }\end{array}$ \\
\hline Verapamil & Inhibit P-glycoprotein & $\begin{array}{l}\text { Decrease intestinal absorption and increased } \\
\text { fexofenadine peak concentration }\end{array}$ \\
\hline Erythromycin & Inhibit P-glycoprotein & $\begin{array}{l}\text { Decrease intestinal absorption and increased } \\
\text { fexofenadine peak concentration }\end{array}$ \\
\hline Ritonavir & Inhibit P-glycoprotein & $\begin{array}{l}\text { Decrease intestinal absorption and increased } \\
\text { fexofenadine peak concentration }\end{array}$ \\
\hline Lopinavir/ritonavir & Inhibit P-glycoprotein & $\begin{array}{l}\text { Decrease intestinal absorption and increased } \\
\text { fexofenadine peak concentration }\end{array}$ \\
\hline St John's Wort & Inhibit P-glycoprotein & $\begin{array}{l}\text { Decrease intestinal absorption and increased } \\
\text { fexofenadine peak concentration }\end{array}$ \\
\hline Omeprazole & Interacts at P-glycoprotein & None \\
\hline Indomethacin & Inhibit multidrug resistant-associated protein & None \\
\hline Probenecid & Inhibit multidrug resistant-associated protein & $\begin{array}{l}\text { Decreased renal clearance and no change in } \\
\text { peak concentration }\end{array}$ \\
\hline Rifamycin & $\begin{array}{l}\text { Inhibit organic anion-transporting } \\
\text { polypeptide }\end{array}$ & None \\
\hline Rifampin & Induction of P-glycoprotein & Increased fexofenadine clearance \\
\hline
\end{tabular}

using MDR1a/1b knockout mice, Tahara et al (2005) showed that P-glycoprotein does have a role in moving fexofenadine from the brain to the plasma, and from the plasma to the liver, but had no effect on fexofenadine biliary excretion.

Cvetkovic et al (1999) found that the human organic anion transporting polypeptide mediates ${ }^{14} \mathrm{C}$-labeled fexofenadine cellular uptake. The bile acid transporter, human sodium taurocholate co-transporting polypeptide, did not exhibit such activity. The authors identified P-glycoprotein as a fexofenadine efflux transporter, using the LLC-PK1 cell, a polarized epithelial cell line that lacks P-glycoprotein, and a derivative cell line (L-MDR1), which overexpresses P-glycoprotein. Oral and intravenous administration of ${ }^{14} \mathrm{C}$-labeled fexofenadine to mice lacking MDR1-encoded P-glycoprotein resulted in 5- and 9-fold increases in the drug's plasma and brain levels, respectively, compared with wild-type mice. A number of drug inhibitors of P-glycoprotein effectively inhibited organic anion transporting polypeptide. Because organic anion transporting polypeptide transporters and P-glycoprotein co-localize in organs of importance to drug disposition, such as the liver, their activity may provide an explanation for the mechanism(s) responsible for fexofenadine disposition, and suggests potentially similar roles in the disposition of other xenobiotics (Cvetkovic et al 1999).
Inhibitors of P-glycoprotein (ketoconazole, itraconazole, verapamil, and erythromycin) inhibited the intestinal absorption of fexofenadine. However, inhibitors of multidrug resistant associated protein (indomethacin, probenecid) and organic anion transporting polypeptide (rifamycin) had no effect upon fexofenadine transport. Rifampin increases fexofenadine clearance, presumably by the induction of P-glycoprotein (Hamman et al 2001). Fexofenadine does not appear to affect the pharmacokinetics of omeprazole, a substrate of P-glycoprotein, suggesting that these two drugs have different transport mechanisms, or fexofenadine does not saturate P-glycoprotein.

Drescher et al (2002) described a number of distinct P-glycoprotein mutations that may affect the transport of fexofenadine. The MDR1 G2577T/C3435T haplotype of P-glycoprotein, in the presence of itraconazole, altered the disposition of fexofenadine, with no change in the elimination half-life and the renal clearance of fexofenadine. Itraconazole resulted in a 3 -fold increase in the peak concentration of fexofenadine and the area under the curve. It increased the mean area under the plasma concentration-time curve of fexofenadine. This suggests that the interaction between itraconazole and fexofenadine may occur at the gut wall before reaching the portal vein circulation. The C3435T mutation does not affect the disposition of fexofenadine. 
However, subjects with the 2677AA/3435CC haplotype had lower plasma fexofenadine concentrations than those with the G2677T/A and C3435T haplotypes (Yi et al 2004). These findings suggest that P-glycoprotein is responsible for the intestinal absorption of fexofenadine.

Van Heeswijk et al (2006) studied the time-dependent interaction between lopinavir/ritonavir and fexofenadine. Ritonavir and lopinavir/ritonavir increased the area under the plasma concentration-time curve for fexofenadine. They did not observe a change in the fexofenadine elimination halflife. They postulated that the increased area under the curve related to increased bioavailability due to P-glycoprotein inhibition. This effect of lopinavir/ritonavir would inhibit the intestinal elimination of fexofenadine. St John's Wort, in a single dose of $900 \mathrm{mg}$, inhibits the intestinal transport of fexofenadine, increasing the maximum plasma concentration of fexofenadine by $45 \%$. St John's wort decreases the oral clearance of fexofenadine by $20 \%$, without changing the half-life and renal clearance (Milne et al 2000; Petri et al 2004; Shon et al 2005; Takahata et al 2004; Tannergren et al 2003; Uno et al 2006; Wang et al 2002). These data suggest that fexofenadine may affect the blood levels of other drugs through its interaction with P-glycoprotein.

Probenecid has been shown to inhibit the interaction of fexofenadine with the organic anion transporter 3 (OAT3) in the kidney (Tahara et al 2006). However, as the renal excretion of fexofenadine is small $(<10 \%)$, the effect upon systemic fexofenadine levels is limited (Robbins et al 1998). There may also be preferential binding of fexofenadine by OAT subtypes. Organic anion transporter Protein 1B3 preferentially accepts fexofenadine over organic anion transporter proteins $1 \mathrm{~B} 1$ and $2 \mathrm{~B} 1$ in human embryonic kidney cells, suggesting that organic anion transporter Protein 1B3 is a transporter involved in hepatic uptake of fexofenadine (Shimizu et al 2005).

Although fexofenadine does not undergo significant metabolism by the P450 CYP 3A4, it does interact with a numbers of drugs at P-glycoprotein and the organic anion transporter polypeptides. These interactions may increase the blood levels of a number of drugs, and increase the risk of adverse effects with concomitant administration of those drugs.

\section{Fruit juices and their effect upon fexofenadine absorption}

Administration of fexofenadine with grapefruit juice reduces the bioavailability of fexofenadine (Banfield et al 2002). This reduction in bioavailability, which also occurs with apple juice, appears to result from preferential inhibition of organic anion transporter polypeptide mediated transport (Dresser et al 2002, 2005; Kamath et al 2005). These data have led to the recommendation that patients should not ingest apple or grapefruit juice while taking fexofenadine.

\section{Mechanism of action (Table 2)}

At 1 to 2 hours following the ingestion of fexofenadine, both the $30 \mathrm{mg}$ and $60 \mathrm{mg}$ doses suppressed the epicutaneous wheal response to histamine through 24 hours post dosing and suppressed the epicutaneous flare response to histamine through 8 hours post dosing (Simons et al 2003). In another study, fexofenadine inhibited the histamine-induced wheal and flare with a maximum effect reached between 1 and 2 hours and lasting through the 12-hour dosing schedule

Table 2 Mechanisms of action of fexofenadine on components of the immune system

\begin{tabular}{|c|c|}
\hline $\begin{array}{l}\text { Component of immune } \\
\text { system }\end{array}$ & Effect of fexofenadine \\
\hline HI receptor & Competitive inhibition \\
\hline $\mathrm{LTC}_{4}, \mathrm{LTD}_{4}$, and $\mathrm{LTE}_{4}$ & Inhibit production \\
\hline $\mathrm{PGE}_{2}$ and $\mathrm{PGF}_{2 \alpha}$ & Inhibit production \\
\hline Cyclo-oxygenase 2 & Competitive inhibition \\
\hline Thromboxane & Inhibit production \\
\hline ¡NOS mRNA & Inhibit production \\
\hline ELAM-I & Inhibit production \\
\hline VCAM-I & Inhibit production \\
\hline Tryptase & Inhibit production \\
\hline \multirow[t]{2}{*}{ Nasal epithelial cells } & $\begin{array}{l}\text { Attenuate electrical resistance } \\
\text { to eosinophils and opsonized } \\
\text { latex beads }\end{array}$ \\
\hline & $\begin{array}{l}\text { Decreased release of IL- } 6 \text { and } \\
\text { TNF } \alpha\end{array}$ \\
\hline Mucosal fibroblasts & $\begin{array}{l}\text { Decreased release of MMP-2 } \\
\text { and MMP-9 }\end{array}$ \\
\hline \multirow[t]{6}{*}{ Eosinophils } & Decreased release of RANTES \\
\hline & Decreased release of IL-8 \\
\hline & Decreased release of GM-CSF \\
\hline & Decreased release of sICAM-I \\
\hline & $\begin{array}{l}\text { Decreased IFN } \gamma \text { - and TNF } \alpha \text { - } \\
\text { induced release of ICAM-I }\end{array}$ \\
\hline & $\begin{array}{l}\text { Decreased trichinella-induced } \\
\text { eosinophilia }\end{array}$ \\
\hline \multirow[t]{3}{*}{ Keratinocyte } & Decreased expression RANTES \\
\hline & Decreased expression of I-TAC \\
\hline & $\begin{array}{l}\text { Decreased expression of MDC } \\
\text { and TARC }\end{array}$ \\
\hline Peripheral blood leukocyte & Decreased production of IL-4 \\
\hline
\end{tabular}


for $60 \mathrm{mg}$, while the fexofenadine $120 \mathrm{mg}$ dose inhibited the histamine-induced wheal and flare for 23 hours. The authors did not note tolerance to the anti-histamine effect over a period of 28 days (Russell et al 1998). Allocco et al (2002), with grants from the NIH and industry, studied the effect of fexofenadine upon the early response to nasal allergen challenge and demonstrated that fexofenadine reduced symptoms and vascular permeability. However, it did not reduce the release of histamine or tryptase. Their data suggest that while fexofenadine antagonizes mediators of the acute allergic response, it does not prevent mast cell degranulation.

Older anti-histamines have anti-cholinergic properties that may induce increased intraocular pressure, leading to glaucoma and prostatism associated with urinary retention. However, in a cholinergic linked capsaicin-induced cough model, pretreatment with fexofenadine had no adverse effect (Dicpinigaitis et al 2003).

In an industry-sponsored study, Juergens et al (2006a) evaluated the effect of fexofenadine on arachidonic acid metabolism in cultured human monocytes. Lipopolysaccharide stimulated human monocytes from healthy volunteers co-cultured with and without fexofenadine, followed by stimulation with zymosan, led to inhibition of $\mathrm{LTC}_{4}, \mathrm{LTD}_{4}$, and $\mathrm{LTE}_{4}$ production. Fexofenadine also inhibited lipopolysaccharide-stimulated production of $\mathrm{PGE}_{2}$ and $\mathrm{PGF}_{2 \alpha}$, which the authors suggest may explain the beneficial effects of fexofenadine upon nasal congestion. In addition, fexofenadine selectively inhibited cyclo-oxygenase 2 , which may also contribute to its apparent anti-inflammatory properties (Juergens et al 2006b). Sakairi et al (2005), in an industrybased study, demonstrated that fexofenadine inhibited the increase in nasal airway resistance in a guinea pig antigeninduced model of rhinitis. They found a similar result with ramatroban, a thromboxane inhibitor. They did not reduce nasal airway resistance with a selective leukotriene antagonist. The authors suggest that fexofenadine may inhibit the release of chemical mediators, including thromboxane, to reduce antigen-induced nasal airway resistance, in part by its inhibitory effect on cyclo-oxygenase 2.

Asano et al (2007), in an industry-sponsored study, evaluated the effect of nitric oxide production by fexofenadine from nasal fibroblasts, which demonstrated inhibition of iNOS mRNA, with the suppression of TNF $\alpha$-induced NO production from nasal fibroblasts. Mice treated for 2 and 3 weeks with fexofenadine had diminished LPS-induced NO production with inhibition of iNOS mRNA expression in lung tissues, suggesting a role for fexofenadine in asthma.
However, Brannan et al (2001) and Fardon et al (2005) did not show a direct benefit of fexofenadine in patients with asthma.

Fexofenadine treatment appeared to decrease endothelial leukocyte adhesion molecule-1 (ELAM-1), vascular cell adhesion molecule-1 (VCAM-1), and tryptase in subjects with chronic idiopathic urticaria, suggesting that fexofenadine may express other anti-inflammatory properties by the modulation of these cytokines (Cassano et al 2002).

Abdelaziz et al (1998) studied the effects of fexofenadine on eosinophil-induced changes in electrical resistance and adherence to human nasal endothelial cells, as well as the effects of fexofenadine on eosinophil adherence and chemotaxis, in the presence and absence of opsonized latex beads. Fexofenadine significantly attenuated the decrease in electrical resistance of the human nasal epithelial cells with exposure to both eosinophils and opsonized latex beads. Human nasal epithelial cells, on exposure to eosinophils with opsonized latex beads, released RANTES, IL-8, GM-CSF, and sICAM-1. Fexofenadine diminished the release of these chemokines with human nasal epithelial cell exposure to eosinophils and opsonized latex beads. In the presence of IFN $\gamma$ and TNF $\alpha$, fexofenadine decreased the expression of ICAM-1, increased the percentage of apoptotic cells, but did not change the expression of LFA-1. Fexofenadine did not change the expression of keratinocyte expression of IL-8 and Mig, but fexofenadine did downmodulate keratinocyte RANTES, I-TAC, MDC, and TARC, suggesting that fexofenadine had a selective effect on $\mathrm{TH} 2$ cytokines, a mechanism by which fexofenadine provided an anti-inflammatory effect. Fexofenadine did not affect peripheral blood leukocyte proliferation induced by Cry $\mathrm{j}$ 1 stimulation. However, fexofenadine significantly inhibited the ability of peripheral blood leukocytes to produce IL-4, but not IFN- $\gamma$ with Cry j 1 stimulation (Asano et al 2004b). Fexofenadine pretreatment reduced the intranasal levels of IL-6 and TNF $\alpha$ in subjects given an intranasal challenge of Parietaria officinalis (Ciprandi et al 2004).

Watanabe et al (2004) studied the effect of fexofenadine upon eosinophilia and systemic anaphylaxis in mice infected with Trichinella spiralis. Fexofenadine provided a dose-dependent suppression of eosinophilia in C57BL/6 mice but not in mast cell-deficient $\mathrm{W} / \mathrm{W}^{\mathrm{v}}$ mice. Fexofenadine suppressed rectal temperature, a marker for systemic anaphylaxis, in C57BL/6 mice. In an IgE-anti-IgE model of anaphylaxis in CBF1 mice, fexofenadine suppressed this same marker of anaphylaxis, without an effect on peripheral IL-5 or eotaxin levels. Fexofenadine diminished mRNA 
expression of RANTES, as well as limited the elaboration of eotaxin from nasal polyp fibroblasts, in response to LPS (Asano et al 2004a).

Fexofenadine inhibited the production of matrix metalloproteinases (MMP) MMP-2 and MMP-9 from nasal polyp and mucosal fibroblasts in response to TNF- $\alpha$, and inhibited MMP mRNA expression and NF- $\kappa B$, but not tissue inhibitor of metalloproteinase (TIMP-1 and TIMP-2) (Asano et al 2004c). Fexofenadine improved performance on the Digit Symbol Substitution Test, but it did not have a blocking effect upon the dopamine transporter (Theunissen et al 2006a, b)

Fexofenadine is primarily prescribed for its $\mathrm{H}_{1}$ antagonist activity. However, it appears to have effects upon other mast cell mediators, as well as mediators produced by other cell types. Fexofenadine, in addition to antagonizing $\mathrm{H}_{1}$ receptors, decreases the production of $\mathrm{LTC}_{4}, \mathrm{LTD}_{4}$, and $\mathrm{LTE}_{4}, \mathrm{PGE}_{2}$, and $\mathrm{PGF}_{2 \alpha}$, inhibits cyclo-oxygenase 2 , inhibits the generation of thromboxane (perhaps through cyclo-oxygenase 2), and limits the iNOS generation of NO, as well as the generation of ICAM-1, ELAM-1, VCAM-1, RANTES, I-TAC, MDC, TARC, MMP-2, MMP-9, and tryptase. Fexofenadine appears to decrease eosinophil adherence, chemotaxis, and opsonization of particles. These effects may decrease the inflammatory responses initiated by an acute allergic reaction and provide a basis for future development of $\mathrm{H} 1$ antagonists with stronger anti-inflammatory effects.

\section{Efficacy and safety}

Fexofenadine reduced airway sensitivity to mannitol compared to placebo. However, fexofenadine did not alter the final percent reduction in $\mathrm{FEV}_{1}$ (Brannan et al 2001). In transfer experiments, fexofenadine prevented the development of airway hyper-responsiveness as well as primary sensitization and challenge, with a decrease in bronchoalveolar lavage and tissue eosinophilia, lymphocyte numbers, and TH2 cytokine production (Gelfand et al 2002). However, fexofenadine did not have an additive effect to inhaled corticosteroid therapy or on inflammatory markers in subjects with atopic asthma (Fardon et al 2005).

In children aged 2 to 5 years with allergic rhinitis, fexofenadine had a frequency of adverse effects no different from placebo. The most frequently involved adverse events were upper respiratory tract infection, fever, infection, and vomiting. Of the adverse events, $8.2 \%$ were attributable to the placebo, and $9.5 \%$ to fexofenadine. There were no clinically relevant differences for laboratory measures, vital signs, and physical examinations (Milgrom et al 2007). Grubbe et al (2007) evaluated effects of fexofenadine oral suspension in 50 children, aged 2 to 5 years. Seven of their subjects experienced 10 adverse events, which resolved without sequelae. One subject suffered pyrexia. Ngamphaiboon et al (2005) studied the efficacy and safety of fexofenadine $30 \mathrm{mg}$ in pediatric patients with allergic rhinitis. No adverse event resulted in dropout. Headache was the most common reported adverse event. In their 88 subjects, they did not appreciate "meaningful change in any electrocardiogram".

In a double blind, two-way crossover study, Simons et al (1996) administered 30 or $60 \mathrm{mg}$ of fexofenadine as a capsule to 14 children with allergic rhinitis (mean age of 9.8 years, with a mean height of $134 \mathrm{~cm}$ and a mean weight of $32.1 \mathrm{~kg}$ ). Somnolence occurred in one child 10 hours after the ingestion of a $30 \mathrm{mg}$ dose. They found no electrocardiogram abnormalities at peak plasma concentrations.

Miyabe et al (2003) studied the effect of fexofenadine upon cedar pollinosis. They found that fexofenadine administered before or after the onset of cedar pollinosis prevented or controlled nasal obstruction, sneeze, and rhinorrhea.

In a multi-center placebo controlled safety and efficacy study of 861 subjects with moderate to severe autumn allergic rhinitis, fexofenadine at doses of $120 \mathrm{mg}$ and $180 \mathrm{mg}$ fexofenadine, given once daily, significantly reduced total symptom score (for nasal congestion), through the 24-hour trough. There were no differences between the two doses of fexofenadine and placebo groups in adverse events, as both subjects and controls reported headache as the most common adverse event (Casale et al 1999).

Fexofenadine had no effect on the quality of life and work productivity in adult subjects with seasonal allergic rhinitis during the peak season for cedar pollinosis (Okubo et al 2005).

Bronsky et al (1998) studied 550 subjects who had previously responded to other anti-histamines for seasonal allergic rhinitis, for 17 days. Subjects sustained significant improvements in total symptom score 1 to 3 hours after the first dose at doses of $40 \mathrm{mg}, 60 \mathrm{mg}$, and $120 \mathrm{mg}$, all twice daily. Adverse events occurred in about $13 \%$ of both the fexofenadine and placebo groups. These authors did not find increases in the $\mathrm{QT}_{\mathrm{C}}$ intervals in their subjects treated with fexofenadine.

In an industry-sponsored study, Meltzer et al (2004) studied the safety and efficacy of fexofenadine in children with seasonal allergic rhinitis. They polled data from 3 double-blind, randomized, placebo-controlled, parallel group, 2-week trials in children ages 6 to 11 years with seasonal allergic rhinitis. The studies used $30 \mathrm{mg}$ twice daily while 2 other studies also used 15 or $60 \mathrm{mg}$ twice daily. 
Adverse events did not differ between the fexofenadine and placebo groups. Headache was the most common adverse event. They did not identify any sedative effect of fexofenadine. Fexofenadine at $30 \mathrm{mg}$ twice daily significantly reduced the total symptom score, sneeze, rhinorrhea, itchy nose/mouth/throat/ears, itchy watery red eyes, and nasal congestion. Kawashima et al (2002) found that doses as low as $20 \mathrm{mg}$ twice daily were effective in the treatment of chronic idiopathic urticaria, and in another study, Kawashima et al (2003) found that fexofenadine improved the pruritus associated with atopic dermatitis more than placebo.

With assistance from industry, Nelson et al (2000) tested the efficacy of fexofenadine in the treatment of chronic idiopathic urticaria. Fexofenadine administered over a period of 4 weeks was better than placebo. They noted no significant differences in the responses to doses between $60 \mathrm{mg}$ twice daily and $240 \mathrm{mg}$ twice daily. All subjects noted improvement in pruritus severity, number of wheals, and interference with sleep. Handa et al (2004) did not find great benefit of fexofenadine $\mathrm{n}$ the treatment of chronic idiopathic urticaria. In an open-label, non-comparative study, Kulthanan et al (2001) studied the efficacy and toxicity of fexofenadine in the treatment of chronic idiopathic urticaria. Of 108 patients enrolled, 10 withdrew for lack of efficacy. Fexofenadine reduced the number of wheals, the severity of itch, interference with sleep, and interference with daily activities. Twenty subjects experienced at least one adverse event. The adverse events included headache, drowsiness, dizziness, increased appetite with weight gain, and cough.

With industry support, Russell et al (1998) studied the fexofenadine dose and subject tolerance to fexofenadine, as well as the drug single dose and steady-state pharmacokinetics in 87 adult subjects. Their subjects tolerated doses of fexofenadine ranging from 10 to $800 \mathrm{mg}$, with no clinically significant trends for cardiac conduction parameters, vital signs, adverse event reporting, or clinical laboratory parameters despite exposure to fexofenadine plasma concentrations as high as $12,250 \mathrm{ng} / \mathrm{mL}$. At doses of 15 and $30 \mathrm{mg}$ twice daily in children aged 6 months to 2 years with allergic rhinitis, treatment-emergent adverse events were similar between the placebo and treatment groups. Vomiting was the most common adverse event. There were no differences between fexofenadine and placebo for vital signs, electrocardiographic results, or physical examination results (Hampel et al 2007). An industry study of the effect of fexofenadine in a single dose up to $800 \mathrm{mg}$ and multiple doses of $690 \mathrm{mg}$ did not appear to change the QTc interval (Pratt et al 1999).
Pinto et al (et al 1999) described a patient on fexofenadine with a prolonged QTc interval. While on fexofenadine, the patient experienced an episode of syncope, with injury to a tooth. Taken off the fexofenadine, the patient's QTc interval normalized. When replaced on fexofenadine $180 \mathrm{mg}$ daily, QTc interval increased and the patient experienced an episode of polymorphic ventricular tachycardia, which progressed to ventricular fibrillation. The authors did not find an alternative reason for the prolonged QTc interval or the ventricular arrhythmia. Industry contested this finding. However, in a response, Pinto et al addressed industry's concerns. (Giraud and Giraud 1999). Craig-McFeely et al (2000, 2001) surveyed general practitioners in Britain for adverse events to fexofenadine. Less than $1 \%$ of respondents stopped the fexofenadine for intolerance. They found no reports of drug interactions. Cardiac events, including palpitations, chest pain, arrhythmia, and chest tightness, but without reports of QTc interval lengthening, resolved upon cessation of the drug. Dhar et al (2000) were unable to find QTc prolongation with fexofenadine.

Hindmarch et al with industry support, studied the effect of fexofenadine upon cognitive and psychomotor function (Hindmarch et al 1999, 2002; Kamei et al 2003; Ridout et al $2003 \mathrm{a}, \mathrm{b})$. The authors tested critical flicker fusion (CFF), choice reaction time (CRT), and assessment of subjective sedation (LARS) after up to $180 \mathrm{mg}$ fexofenadine, from 1 to 24 hours. They were unable to find a difference between fexofenadine and placebo. Stone et al (1999) studied the central effects of fexofenadine (120, 180 and $240 \mathrm{mg}$ ) on digit symbol substitution, tracking and vigilance tasks and on objective sleepiness (multiple sleep latency test) and subjective sleepiness. They found no effect of the fexofenadine on any of these variables. Potter et al (2003) were unable to find differences in reaction time, decision-making, and driver behavior with and without fexofenadine $180 \mathrm{mg}$ compared to placebo. They found no differences between the fexofenadine and the placebo groups. Nicholson et al (2000) found that fexofenadine in doses of $120 \mathrm{~g}, 180 \mathrm{mg}$, and $240 \mathrm{mg}$ did not affect digit symbol substitution, tracking, vigilance tasks, multiple sleep latencies, and subjective sleepiness. Mansfield et al (2003) found that fexofenadine at a dose of $180 \mathrm{mg}$ did not change self-reported drowsiness, omission errors, and response time. Bower et al (2003) studied the effects of single-dose fexofenadine, diphenhydramine, and placebo on cognitive performance in flight personnel. Although diphenhydramine resulted in significant psychomotor decrements, the effect of fexofenadine was not different from placebo. In an industry-supported study, Tashiro et al (2005) studied 
the effect of fexofenadine upon brake reaction time, while using a cellular phone. Compared to hydroxyzine, fexofenadine did not impair brake reaction time in otherwise healthy subjects. Weiler et al (2000) compared the effects of fexofenadine, diphenhydramine, and alcohol on driving performance. Subjects received one of these drugs or placebo, weekly, 1 hour prior to driving. Subjects had significantly better coherence after taking alcohol or fexofenadine than after taking diphenhydramine. Lane keeping (steering instability and crossing the centerline) was impaired after alcohol and diphenhydramine use compared with fexofenadine use. Alcohol increased the mean response time to stop the vehicle compared to fexofenadine. Self-reported drowsiness did not predict lack of coherence and weakly related to the minimum following distance, steering instability, and left lane excursion. In a review by Banerji et al (2007), the authors found that fexofenadine was less sedating than diphenhydramine.

Graft et al (2001), in an industry-sponsored study, demonstrated the safety of fexofenadine in 875 children, 6 to 11 years of age, treated for seasonal allergic rhinitis. They administered $15 \mathrm{mg}, 30 \mathrm{mg}$, or $60 \mathrm{mg}$, twice daily. Ten of their subjects ( 5 in the fexofenadine group and 5 in the placebo group) stopped the medication because of an adverse event, which included upper respiratory congestion, otitis media, and asthma, although the authors could not link any of the adverse events to the drug. They reported no changes in electrocardiograms.

Saraswat et al (2006) presented a case of stable psoriasis, who developed a severe pustular flare within 24 hours of taking fexofenadine. Following resolution of the pustular psoriasis, they rechallenged the patient with fexofenadine, with recurrence of the rash. These studies support the contention that fexofenadine is effective for the treatment of allergic rhinits and chronic idiopathic urticaria, perhaps without benefit to patients with asthma. With the possible exception of rare adverse cardiac and cutaneous events, fexofenadine appears no more toxic than placebo when administered in the absence of other drugs.

\section{Conclusion}

The FDA approved fexofenadine for treatment of the symptoms of allergic rhinitis and chronic idiopathic urticaria. The drug appeared effective in the treatment of its indicated conditions. Subjects tolerated fexofenadine well. However, concern remains regarding fexofenadine's interactions with other medications that use the P-glycoprotein and the organic anion transporter peptides, which may result in an increased risk of adverse events to those other medications.
This concern comes from the pharmacokinetic data, which suggest that although only a small proportion of fexofenadine is metabolized, fexofenadine moves into and out of the blood and tissues by at least P-glycoprotein and organic anion transporter peptides, which transport a number of other medications. In addition to blocking $\mathrm{H}_{1}$ receptors, fexofenadine appears to diminish the production of $\mathrm{LTC}_{4}, \mathrm{LTD}_{4}$, and $\mathrm{LTE}_{4}, \mathrm{PGE}_{2}$, and $\mathrm{PGF}_{2 \alpha}$; inhibits cyclo-oxygenase 2; inhibits the generation of thromboxane (perhaps through cyclo-oxygenase 2); and limits iNOS generation of NO, as well as ICAM-1, ELAM-1, VCAM-1, RANTES, I-TAC, MDC, TARC, MMP-2, MMP-9, and tryptase, which may contribute to its benefit.

\section{Disclosures}

Neither author has conflicts of interest to disclose.

\section{References}

Abdelaziz MM, Devalia JL, Khair OA, et al. 1998. Effect of fexofenadine on eosinophil-induced changes in epithelial permeability and cytokine release from nasal epithelial cells of patients with seasonal allergic rhinitis. J Allergy Clin Immunol, 101:410-20.

Adenot M, Lahana R, Adenot M, et al. 2004. Blood-brain barrier permeation models: discriminating between potential CNS and non-CNS drugs including P-glycoprotein substrates. J Chem Inf Comput Sci, 44:239-48.

Akiyama S, Cornwell MM, Kuwano M, et al. 1988. Most drugs that reverse multidrug resistance also inhibit photoaffinity labeling of P-glycoprotein by a vinblastine analog. Mol Pharmacol, 33:144-7

Allocco FT, Votypka V, deTineo M, et al. 2002. Effects of fexofenadine on the early response to nasal allergen challenge. Ann Allergy Asthma Immunol, 89:578-84.

Asano K, Kanai K, Furuta A, et al. 2007. Suppressive activity of fexofenadine hydrochloride on nitric oxide production in-vitro and in-vivo. J Pharm Pharmacol, 59:1389-95.

Asano K, Kanai K, Suzaki H, et al. 2004a. Suppressive activity of fexofenadine hydrochloride on the production of eosinophil chemoattractants from human nasal fibroblasts in vitro. Arzneimittelforschung, $54: 436-43$.

Asano K, Kanai K, Suzaki H, et al. 2004b. Suppressive activity of fexofenadine hydrochloride on thymus- and activation-regulated chemokine production from human peripheral blood leukocytes in response to antigenic stimulation in vitro. Int Arch Allergy Immunol, 133:267-75.

Asano K, Kanai KI, Suzaki H, et al. 2004c. Suppressive activity of fexofenadine hydrochloride on metalloproteinase production from nasal fibroblasts in vitro. Clin Exp Allergy, 34:1890-8.

Baltes S, Gastens AM, Fedrowitz M, et al. 2007. Differences in the transport of the antiepileptic drugs phenytoin, levetiracetam and carbamazepine by human and mouse P-glycoprotein. Neuropharmacology, 52:333-46.

Banerji A, Long AA, Camargo CA Jr. 2007. Diphenhydramine versus nonsedating antihistamines for acute allergic reactions: a literature review. Allergy Asthma Proc, 28:418-26.

Banfield C, Gupta S, Marino M, et al. 2002. Grapefruit juice reduces the oral bioavailability of fexofenadine but not desloratadine. Clin Pharmacokinet, 41:311-8.

Bielory L. Leonov A. 2008. Stereoconfiguration of antiallergic and immunologic drugs. Ann Allerg Asthma Immunol, 100:1-8.

Bower EA, Moore JL, Moss M, et al. 2003. The effects of single-dose fexofenadine, diphenhydramine, and placebo on cognitive performance in flight personnel. Aviat Space Environ Med, 74:145-52. 
Brannan JD, Anderson SD, Gomes K, et al. 2001. Fexofenadine decreases sensitivity to and montelukast improves recovery from inhaled mannitol. Am J Respir Crit Care Med, 163:1420-5.

Bronsky EA, Falliers CJ, Kaiser HB, et al. 1998. Effectiveness and safety of fexofenadine, a new nonsedating H1-receptor antagonist, in the treatment of fall allergies. Allergy Asthma Proc, 19:135-41.

Casale TB, Andrade C, Qu R, et al. 1999. Safety and efficacy of once-daily fexofenadine $\mathrm{HCl}$ in the treatment of autumn seasonal allergic rhinitis. Allergy Asthma Proc, 20:193-8.

Cassano N, Filotico R, D'Argento V, et al. 2002. In vivo anti-inflammatory effects of fexofenadine in chronic idiopathic urticaria. $J$ Eur Acad Dermatol Venereol, 16:421-2.

Charuk JH, Loo TW, Clarke DM, et al. 1994. Interaction of rat kidney P-glycoprotein with a urinary component and various drugs including cyclosporin A. Am J Physiol, 266:F66-75.

Chiou WL, Chung SM, Wu TC. 2000. Potential role of P-glycoprotein in affecting hepatic metabolism of drugs. Pharm Res, 17:903-5.

Choi SU, Park SH, Kim KH, et al. 1998. The bisbenzylisoquinoline alkaloids, tetrandine and fangchinoline, enhance the cytotoxicity of multidrug resistance-related drugs via modulation of P-glycoprotein. Anticancer Drugs, 9:255-61.

Ciprandi G, Cirillo I, Vizzaccaro A, et al. 2004. Mizolastine and fexofenadine modulate cytokine pattern after nasal allergen challenge. Allerg Immunol (Paris), 36:146-50.

Craig-McFeely PM, Acharya NV, Shakir SA, et al. 2001. Evaluation of the safety of fexofenadine from experience gained in general practice use in England in 1997. Eur J Clin Pharmacol, 57:313-20.

Craig-McFeely PM, Freemantle SL, Pearce GL, et al. 2000. QT lengthening and life-threatening arrhythmias associated with fexofenadine. Br J Gen Pract, 50:148.

Crowe A, Ilett KF, Karunajeewa HA, et al. 2006a. Role of P glycoprotein in absorption of novel antimalarial drugs. Antimicrob Agents Chemother, 50:3504-6.

Crowe A, Teoh YK, Crowe A, et al. 2006b. Limited P-glycoprotein mediated efflux for anti-epileptic drugs. J Drug Target, 14:291-300.

Cvetkovic M, Leake B, Fromm MF, et al. 1999. OATP and P-glycoprotein transporters mediate the cellular uptake and excretion of fexofenadine. Drug Metab Dispos, 27:866-71.

Dhar S, Hazra PK, Malakar S, et al. 2000. Fexofenadine-induced QT prolongation: a myth or fact? Br J Dermatol, 142:1260-1.

Dicpinigaitis PV, Gayle YE, Dicpinigaitis PV, et al. 2003. Effect of the second-generation antihistamine, fexofenadine, on cough reflex sensitivity and pulmonary function. $\mathrm{Br} J$ Clin Pharmacol, 56:501-4.

DiDiodato G, Sharom FJ. 1997. Interaction of combinations of drugs, chemosensitizers, and peptides with the P-glycoprotein multidrug transporter. Biochem Pharmacol, 53:1789-97.

Doran A, Obach RS, Smith BJ, et al. 2005. The impact of P-glycoprotein on the disposition of drugs targeted for indications of the central nervous system: evaluation using the MDR1A/1B knockout mouse model. Drug Metab Dispos, 33:165-74.

Drescher S, Schaeffeler E, Hitzl M, et al. 2002. MDR1 gene polymorphisms and disposition of the P-glycoprotein substrate fexofenadine. Br J Clin Pharmacol, 53:526-34.

Dresser GK, Bailey DG, Leake BF, et al. 2002. Fruit juices inhibit organic anion transporting polypeptide-mediated drug uptake to decrease the oral availability of fexofenadine. Clin Pharmacol Ther, 71:11-20.

Dresser GK, Kim RB, Bailey DG, et al. 2005. Effect of grapefruit juice volume on the reduction of fexofenadine bioavailability: possible role of organic anion transporting polypeptides. Clin Pharmacol Ther, 77:170-7.

Ejsing TB, Morling N, Linnet K, et al. 2007. A review on the relation between the brain-serum concentration ratio of drugs and the influence of P-glycoprotein. Drug Metabol Drug Interact, 22:113-29

Elsinga PH, Hendrikse NH, Bart J, et al. 2004. PET Studies on P-glycoprotein function in the blood-brain barrier: how it affects uptake and binding of drugs within the CNS. Curr Pharm Des, 10:1493-503.
Faassen F, Vogel G, Spanings H, et al. 2003. Caco-2 permeability, P-glycoprotein transport ratios and brain penetration of heterocyclic drugs. Int J Pharm, 263:113-22.

Fardon TC, Lee DK, Hodge MR, et al. 2005. Addition of fexofenadine to inhaled corticosteroid therapy to reduce inflammatory biomarkers in atopic asthma. Ann Allergy Asthma Immunol, 95:259-65.

Feng B, Mills JB, Davidson RE, et al. 2008. In vitro P-glycoprotein assays to predict the in vivo interactions of P-glycoprotein with drugs in the central nervous system. Drug Metab Dispos, 36:268-75.

Fokkens WJ, Broekhuis-Fluitsma DM, Rijntjes E, et al. 1991. Langerhans cells in nasal mucosa of patients with grass pollen allergy. Immunobiology, 182:135-42.

Fromm MF. 2000. P-glycoprotein: a defense mechanism limiting oral bioavailability and CNS accumulation of drugs. Int J Clin Pharmacol Ther, 38:69-74.

Garrigues A, Nugier J, Orlowski S, et al. 2002. A high-throughput screening microplate test for the interaction of drugs with P-glycoprotein. Anal Biochem, 305:106-14.

Gelfand EW, Cui ZH, Takeda K, et al. 2002. Fexofenadine modulates T-cell function, preventing allergen-induced airway inflammation and hyperresponsiveness. J Allergy Clin Immunol, 110:85-95.

Giraud T, Giraud T. 1999. QT lengthening and arrhythmias associated with fexofenadine. [comment]. Lancet, 353:2072-3.

Gouaze V, Liu YY, Prickett CS, et al. 2005. Glucosylceramide synthase blockade down-regulates P-glycoprotein and resensitizes multidrugresistant breast cancer cells to anticancer drugs. Cancer Res, 65:3861-7.

Graft DF, Bernstein DI, Goldsobel A, et al. 2001. Safety of fexofenadine in children treated for seasonal allergic rhinitis. Ann Allergy Asthma Immunol, 87:22-6.

Grewal IS, Flavell RA. 1996. A central role of CD40 ligand in the regulation of CD4+ T-cell responses. Immunol Today, 17:410-4.

Grubbe RE Nayak A, Kittner B, et al. 2007. The pharmacokinetics (PK), safety and tolerability of fexofenadine HCL $6 \mathrm{mg} / \mathrm{mL}$ suspension in children with allergic rhinitis (AR): a multicenter, open-label, singledose study. J Allergy Clin Immunol, 119:S143.

Hamman MA, Bruce MA, Haehner-Daniels BD, et al. 2001. The effect of rifampin administration on the disposition of fexofenadine. Clin Pharmacol Ther, 69:114-21.

Hampel FC, Kittner B, van Bavel JH, et al. 2007. Safety and tolerability of fexofenadine hydrochloride, 15 and $30 \mathrm{mg}$, twice daily in children aged 6 months to 2 years with allergic rhinitis. Ann Allergy Asthma Immunol, 99:549-54.

Handa S, Dogra S, Kumar B, et al. 2004. Comparative efficacy of cetirizine and fexofenadine in the treatment of chronic idiopathic urticaria. [see comment]. J Dermatolog Treat, 15:55-7.

Hanko E, Tommarello S, Watchko JF, et al. 2003. Administration of drugs known to inhibit P-glycoprotein increases brain bilirubin and alters the regional distribution of bilirubin in rat brain.[see comment]. Pediatr Res, 54:441-5.

Hayeshi R, Masimirembwa C, Mukanganyama S, et al. 2006. The potential inhibitory effect of antiparasitic drugs and natural products on P-glycoprotein mediated efflux. Eur J Pharm Sci 29:70-81.

Hindmarch I, Shamsi Z, Kimber S, et al. 2002. An evaluation of the effects of high-dose fexofenadine on the central nervous system: a doubleblind, placebo-controlled study in healthy volunteers. Clin Exp Allergy, 32:133-9.

Hindmarch I, Shamsi Z, Stanley N, et al. 1999. A double-blind, placebocontrolled investigation of the effects of fexofenadine, loratadine and promethazine on cognitive and psychomotor function. $\mathrm{Br} J$ Clin Pharmacol, 48:200-6.

Hirano H. 1989. [Studies on the degranulation and histamine release of purified rat peritoneal mast cells. The inhibitory effect of histamine and other chemicals]. Nippon Ika Daigaku Zasshi, 56:392-9.

Ibrahim S, Peggins J, Knapton A, et al. 2000. Influence of antipsychotic, antiemetic, and $\mathrm{Ca}(2+)$ channel blocker drugs on the cellular accumulation of the anticancer drug daunorubicin: P-glycoprotein modulation. J Pharmacol Exp Ther, 295:1276-83. 
Ishizaka T, Ishizaka K. 1977. Immunological events at the surface of basophil granulocytes and mast cells which induce degranulation. Scand J Respir Dis Suppl, 98:13-22.

Ito T, Yano I, Tanaka K, et al. 1997. Transport of quinolone antibacterial drugs by human P-glycoprotein expressed in a kidney epithelial cell line, LLC-PK1. J Pharmacol Exp Ther, 282:955-60.

Jette L, Murphy GF, Leclerc JM, et al. 1995. Interaction of drugs with P-glycoprotein in brain capillaries. Biochem Pharmacol, 50:1701-9.

Johnson WW. 2002. P-glycoprotein-mediated efflux as a major factor in the variance of absorption and distribution of drugs: modulation of chemotherapy resistance. Methods Find Exp Clin Pharmacol, 24:501-14.

Juergens UR, Darlath W, Stober M, et al. 2006a. Differential effects of fexofenadine on arachidonic acid metabolism in cultured human monocytes. Pharmacology, 76:40-5.

Juergens UR, Gillissen A, Uen S, et al. 2006b. New evidence of H1-receptor independent $\mathrm{COX}-2$ inhibition by fexofenadine $\mathrm{HCl}$ in vitro. Pharmacology, 78:129-35.

Kamath AV, Yao M, Zhang Y, et al. 2005. Effect of fruit juices on the oral bioavailability of fexofenadine in rats. J Pharm Sci, 94:233-9.

Kamei H, Noda Y, Ishikawa K, et al. 2003. Comparative study of acute effects of single doses of fexofenadine, olopatadine, d-chlorpheniramine and placebo on psychomotor function in healthy volunteers. Hum Psychopharmacol, 18:611-8.

Kawashima M, Harada S, Tango T, et al. 2002. Review of fexofenadine in the treatment of chronic idiopathic urticaria. Int J Dermatol, 41:701-6.

Kawashima M, Tango T, Noguchi T, et al. 2003. Addition of fexofenadine to a topical corticosteroid reduces the pruritus associated with atopic dermatitis in a 1-week randomized, multicentre, double-blind, placebocontrolled, parallel-group study. Br J Dermatol, 148:1212-21.

Ketabi-Kiyanvash N, Weiss J, Haefeli WE, et al. 2003. P-glycoprotein modulation by the designer drugs methylenedioxymethamphetamine, methylenedioxyethylamphetamine and paramethoxyamphetamine. Addict Biol, 8:413-8.

Kharasch ED, Walker A, Hoffer C, et al. 2005. Evaluation of first-pass cytochrome P4503A (CYP3A) and P-glycoprotein activities using alfentanil and fexofenadine in combination. J Clin Pharmacol, 45:79-88.

Kim RB, Kim RB. 2002. Drugs as P-glycoprotein substrates, inhibitors, and inducers. Drug Metab Rev, 34:47-54.

King M, Su W, Chang A, Zuckerman A, et al. 2001. Transport of opioids from the brain to the periphery by P-glycoprotein: peripheral actions of central drugs.[see comment]. Nat Neurosci, 4:268-74.

Kulthanan K, Gritiyarangsan P, Sitakalin C, et al. 2001. Multicenter study of the efficacy and safety of fexofenadine $60 \mathrm{mg}$. twice daily in 108 Thai patients with chronic idiopathic urticaria. $J$ Med Assoc Thai, 84:153-9.

Lee CH, Lee CH. 2002. Differential regulation of P-glycoprotein genes in primary rat hepatocytes by collagen sandwich and drugs. $J$ Cell Biochem, 86:12-20.

Leung DY. 1998. Molecular basis of allergic diseases. Mol Genet Metab, 63:157-67.

Leung S, Bendayan R. 1999. Role of P-glycoprotein in the renal transport of dideoxynucleoside analog drugs. Can J Physiol Pharmacol, 77:625-30.

Ling V. 1992. Charles F. Kettering Prize. P-glycoprotein and resistance to anticancer drugs. Cancer, 69:2603-9.

Litman T, Skovsgaard T, Stein WD, et al. 2003. Pumping of drugs by P-glycoprotein: a two-step process? J Pharmacol Exp Ther, 307:846-53.

Loo TW, Bartlett MC, Clarke DM, et al. 2003. Simultaneous binding of two different drugs in the binding pocket of the human multidrug resistance P-glycoprotein. J Biol Chem, 278:39706-10.

Makowski P, Pikula S. 1997. Participation of the multispecific organic anion transporter in hepatobiliary excretion of glutathione S-conjugates, drugs and other xenobiotics. Pol J Pharmacol, 49:387-94.

Mansfield L, Mendoza C, Flores J, et al. 2003. Effects of fexofenadine, diphenhydramine, and placebo on performance of the test of variables of attention (TOVA). [erratum Ann Allergy Asthma Immunol, 2003; 91(2):167]. Ann Allergy Asthma Immunol, 90:554-9.
Meltzer EO, Scheinmann P, Rosado Pinto JE, et al. 2004. Safety and efficacy of oral fexofenadine in children with seasonal allergic rhinitis - a pooled analysis of three studies. Pediatr Allergy Immunol, 15:253-60.

Milgrom H, Kittner B, Lanier R, et al. 2007. Safety and tolerability of fexofenadine for the treatment of allergic rhinitis in children 2 to 5 years old. Ann Allergy Asthma Immunol, 99:358-63.

Milne RW, Larsen LA, Jorgensen KL, et al. 2000. Hepatic disposition of fexofenadine: influence of the transport inhibitors erythromycin and dibromosulphothalein. Pharm Res, 17:1511-5.

Miura M, Uno T, Tateishi T, et al. 2007. Pharmacokinetics of fexofenadine enantiomers in healthy subjects. Chirality, 19:223-7.

Miyabe S, Koizuka I, Ochi K, et al. 2003. Effect of fexofenadine hydrochloride on cedar pollinosis. Auris Nasus Larynx, 30(Suppl):S61-8.

Mollgard L, Hellberg E, Smolowicz A, et al. 2001. Interactions between P-glycoprotein and drugs used in the supportive care of acute myeloid leukemia patients. Leuk Lymphoma, 42:177-85.

Morrison D, Sahasranaman S. 2007. The $30 \mathrm{mg}$ dose of fexofenadine HCL $6 \mathrm{mg} / \mathrm{mL}$ suspension is bioequivalent to the marketed $30 \mathrm{mg}$ tablet in healthy adult subjects under fasted conditions: a randomized crossover, open-label study. J Allergy Clin Immunol, 119:S143.

Nelson HS, Reynolds R, Mason J, et al. 2000. Fexofenadine $\mathrm{HCl}$ is safe and effective for treatment of chronic idiopathic urticaria. Ann Allergy Asthma Immunol, 84:517-22.

Neuhoff S, Langguth P, Dressler C, et al. 2000. Affinities at the verapamil binding site of MDR1-encoded P-glycoprotein: drugs and analogs, stereoisomers and metabolites. Int J Clin Pharmacol Ther, 38:168-79.

Ngamphaiboon J, Direkwattanachai C, Visitsunthorn N, et al. 2005. The efficacy and safety of $30 \mathrm{mg}$ fexofenadine $\mathrm{HCl}$ bid in pediatric patients with allergic rhinitis. Asian Pac J Allergy Immunol, 23:169-74.

Nicholson AN, Stone BM, Turner C, et al. 2000. Antihistamines and aircrew: usefulness of fexofenadine. Aviat Space Environ Med, 71:2-6.

Okubo K, Gotoh M, Shimada K, et al. 2005. Fexofenadine improves the quality of life and work productivity in Japanese patients with seasonal allergic rhinitis during the peak cedar pollinosis season. Int Arch Allergy Immunol, 136:148-54.

Orlowski S, Garrigos M. 1999. Multiple recognition of various amphiphilic molecules by the multidrug resistance P-glycoprotein: molecular mechanisms and pharmacological consequences coming from functional interactions between various drugs. Anticancer Res, 19:3109-23.

Pascaud C, Garrigos M, Orlowski S. 1998. Multidrug resistance transporter P-glycoprotein has distinct but interacting binding sites for cytotoxic drugs and reversing agents. Biochem $J, 333: 351-8$.

Petri N, Tannergren C, Rungstad D, et al. 2004. Transport characteristics of fexofenadine in the Caco-2 cell model. Pharm Res, 21:1398-404.

Pinto YM, van Gelder IC, Heeringa M, et al. 1999. QT lengthening and lifethreatening arrhythmias associated with fexofenadine. [see comment]. Lancet, 353:980.

Potter PC, Schepers JM, Van Niekerk CH, et al. 2003. The effects of fexofenadine on reaction time, decision-making, and driver behavior. Ann Allergy Asthma Immunol, 91:177-81.

Pratt C, Brown AM, Rampe D, et al. 1999. Cardiovascular safety of fexofenadine HCl. Clin Exp Allergy, 29(Suppl 3):212-6.

Rebbeor JF, Senior AE. 1998. Effects of cardiovascular drugs on ATPase activity of P-glycoprotein in plasma membranes and in purified reconstituted form. Biochim Biophys Acta, 1369:85-93.

Ridout F, Hindmarch I, Ridout F, et al. 2003a. The effects of acute doses of fexofenadine, promethazine, and placebo on cognitive and psychomotor function in healthy Japanese volunteers. Ann Allergy Asthma Immunol, 90:404-10.

Ridout F, Shamsi Z, Meadows R, et al. 2003b. A single-center, randomized, double-blind, placebo-controlled, crossover investigation of the effects of fexofenadine hydrochloride $180 \mathrm{mg}$ alone and with alcohol, with hydroxyzine hydrochloride $50 \mathrm{mg}$ as a positive internal control, on aspects of cognitive and psychomotor function related to driving a car. Clin Ther, 25:1518-38. 
Robbins DK, Castles MA, Pack DJ, et al. 1998. Dose proportionality and comparison of single and multiple dose pharmacokinetics of fexofenadine (MDL 16455) and its enantiomers in healthy male volunteers. Biopharm Drug Dispos, 19:455-63.

Russell T, Stoltz M, Weir S, et al. 1998. Pharmacokinetics, pharmacodynamics, and tolerance of single- and multiple-dose fexofenadine hydrochloride in healthy male volunteers. Clin Pharmacol Ther, 64:612-21.

Safa AR, Safa AR. 2004. Identification and characterization of the binding sites of P-glycoprotein for multidrug resistance-related drugs and modulators. Curr Med Chem Anti-Canc Agents, 4:1-17.

Sakairi T, Suzuki K, Makita S, et al. 2005. Effects of fexofenadine hydrochloride in a guinea pig model of antigen-induced rhinitis. Pharmacology, 75:76-86.

Saraswat A, Saraswat M, Saraswat A, et al. 2006. Pustular exacerbation of psoriasis due to fexofenadine. Clin Exp Dermatol, 31:477-8.

Savolainen J, Edwards JE, Morgan ME, et al. 2002. Effects of a P-glycoprotein inhibitor on brain and plasma concentrations of anti-human immunodeficiency virus drugs administered in combination in rats. Drug Metab Dispos, 30:479-82.

Schinkel AH, Wagenaar E, Mol CA, et al. 1996. P-glycoprotein in the blood-brain barrier of mice influences the brain penetration and pharmacological activity of many drugs. J Clin Invest, 97:2517-24.

Sharom FJ. 1997. The P-glycoprotein efflux pump: how does it transport drugs?[see comment]. J Membr Biol, 160:161-75.

Shimizu M, Fuse K, Okudaira K, et al. 2005. Contribution of OATP (organic anion-transporting polypeptide) family transporters to the hepatic uptake of fexofenadine in humans. Drug Metab Dispos, 33:1477-81.

Shirasaka Y, Onishi Y, Sakurai A, et al. 2006. Evaluation of human P-glycoprotein (MDR1/ABCB1) ATPase activity assay method by comparing with in vitro transport measurements: Michaelis-Menten kinetic analysis to estimate the affinity of P-glycoprotein to drugs. Biol Pharm Bull, 29:2465-71.

Shon JH, Yoon YR, Hong WS, et al. 2005. Effect of itraconazole on the pharmacokinetics and pharmacodynamics of fexofenadine in relation to the MDR1 genetic polymorphism. Clin Pharmacol Ther, 78:191-201.

Shukla S, Sauna ZE, Ambudkar SV. 2008. Evidence for the interaction of imatinib at the transport-substrate site(s) of the multidrugresistance-linked $\mathrm{ABC}$ drug transporters $\mathrm{ABCB} 1$ (P-glycoprotein) and ABCG2.[comment]. Leukemia, 22:445-7.

Simons FE, Bergman JN, Watson WT, et al. 1996. The clinical pharmacology of fexofenadine in children. J Allergy Clin Immunol, 98:1062-4.

Simons F, Estelle R, Semus M, et al. 2003. H1-antihistaminic activity of cetirizine and fexofenadine in allergic children. Pediatr Allergy Immunol, 14:207-11.

Smit JW, Duin E, Steen H, et al. 1998. Interactions between P-glycoprotein substrates and other cationic drugs at the hepatic excretory level. Br J Pharmacol, 123:361-70.

Stoltz M, Arumugham T, Lippert C, et al. 1997. Effect of food on the bioavailability of fexofenadine hydrochloride (MDL 16455A). Biopharm Drug Dispos, 18:645-8.

Stone BM, Turner C, Mills SL, et al. 1999. Studies into the possible central effects of the H-1 receptor antagonist, fexofenadine. Int Arch Allergy Immunol, 118:338.

Storch CH, Theile D, Lindenmaier H, et al. 2007. Comparison of the inhibitory activity of anti-HIV drugs on P-glycoprotein. Biochem Pharmacol, 73:1573-81.
Tahara H, Kusuhara H, Fuse E, et al. 2005. P-glycoprotein plays a major role in the efflux of fexofenadine in the small intestine and blood-brain barrier, but only a limited role in its biliary excretion. [erratum Drug Metab Dispos, 200634(6):1079]. Drug Metab Dispos, 33:963-8.

Tahara H, Kusuhara H, Maeda K, et al. 2006. Inhibition of oat3-mediated renal uptake as a mechanism for drug-drug interaction between fexofenadine and probenecid. Drug Metab Dispos, 34:743-7.

Takahata T, Yasui-Furukori N, Yoshiya G, et al. 2004. Fexofenadine does not affect omeprazole pharmacokinetics: both are putative P-glycoprotein substrates. Basic Clin Pharmacol Toxicol, 94:252-6.

Tannergren C, Knutson T, Knutson L, et al. 2003. The effect of ketoconazole on the in vivo intestinal permeability of fexofenadine using a regional perfusion technique. Br J Clin Pharmacol, 55:182-90.

Tashiro M, Horikawa E, Mochizuki H, et al. 2005. Effects of fexofenadine and hydroxyzine on brake reaction time during car-driving with cellular phone use. Hum Psychopharmacol, 20:501-9.

Terao T, Hisanaga E, Sai Y, et al. 1996. Active secretion of drugs from the small intestinal epithelium in rats by P-glycoprotein functioning as an absorption barrier. J Pharm Pharmacol, 48:1083-9.

Theunissen EL, Jonkman LM, Kuypers KP, et al. 2006a. A combined neurophysiological and behavioural study into the stimulating effects of fexofenadine on performance. J Psychopharmacol, 20:496-505.

Theunissen EL, van Kroonenburgh MJ, van Deursen JA, et al. 2006b. Stimulating effects of the antihistamine fexofenadine: testing the dopamine transporter hypothesis. Psychopharmacology (Berl), 187:95-102.

Uno T, Shimizu M, Sugawara K, et al. 2006. Lack of dose-dependent effects of itraconazole on the pharmacokinetic interaction with fexofenadine. Drug Metab Dispos, 34:1875-9.

van Heeswijk RP, Bourbeau M, Campbell P, et al. 2006. Time-dependent interaction between lopinavir/ritonavir and fexofenadine. $J$ Clin Pharmacol, 46:758-67.

Vercelli D, Jabara HH, Arai K, et al. 1989. Induction of human IgE synthesis requires interleukin 4 and $\mathrm{T} / \mathrm{B}$ cell interactions involving the $\mathrm{T}$ cell receptor/CD3 complex and MHC class II antigens. J Exp Med, 169:1295-307.

Wang JS, Zhu HJ, Markowitz JS, et al. 2006. Evaluation of antipsychotic drugs as inhibitors of multidrug resistance transporter P-glycoprotein. Psychopharmacology (Berl), 187:415-23.

Wang Z, Hamman MA, Huang SM, et al. 2002. Effect of St John's wort on the pharmacokinetics of fexofenadine. [see comment]. Clin Pharmacol Ther, 71:414-20.

Watanabe N, Matsuda E, Masuda A, et al. 2004. The effects of fexofenadine on eosinophilia and systemic anaphylaxis in mice infected with Trichinella spiralis. Int Immunopharmacol, 4:367-75.

Weiler JM, Bloomfield JR, Woodworth GG, et al. 2000. Effects of fexofenadine, diphenhydramine, and alcohol on driving performance. A randomized, placebo-controlled trial in the Iowa driving simulator. [see comment]. Ann Intern Med, 132:354-63.

Weiss J, Kerpen CJ, Lindenmaier H, et al. 2003. Interaction of antiepileptic drugs with human P-glycoprotein in vitro. $J$ Pharmacol Exp Ther, 307:262-7.

Yi SY, Hong KS, Lim HS, et al. 2004. A variant 2677A allele of the MDR1 gene affects fexofenadine disposition. Clin Pharmacol Ther, $76: 418-27$. 
